Indonesian Journal of Electronics and Instrumentation Systems (IJEIS)

Vol.9, No.2, October 2019, pp. 203 214

ISSN (print): 2088-3714, ISSN (online): 2460-7681

DOI: https://doi.org/10.22146/ijeis.50377

\title{
Peningkatan Skalabilitas Mini Weather Station Portable berbasis Internet of Things
}

\author{
Nur Achmad Sulistyo Putro*1, Catur Atmaji ${ }^{2}$, Kristiawan Devianto ${ }^{3}$, \\ Zandy Yudha Perwira ${ }^{4}$ \\ 1,2,3,4 Departemen Ilmu Komputer dan Elektronika, FMIPA UGM, Yogyakarta \\ e-mail: *11nur.achmad.s.p@ugm.ac.id, ${ }^{2}$ catur_atmaji@ugm.ac.id, \\ ${ }^{3}$ kristiawan.devianto@mail.ugm.ac.id, ${ }^{4}$ zandy.yudha.p@mail.ugm.ac.id
}

\begin{abstract}
Abstrak
Indonesia merupakan negara yang memiliki cuaca yang unik. Selain memberikan potensi kekayaan alam yang berlimpah, kondisi ini juga menyebabkan Indonesia diintai oleh bencana yang sewaktu-waktu dapat terjadi. Untuk mengurangi ancaman kerugian yang terjadi akibat bencana tersebut, pengamatan unsur cuaca menggunakan alat weather station biasanya menjadi salah satu solusi yang dapat digunakan. Pengembangan sistem terkait dengan pemantauan lingkungan dan stasiun cuaca bukanlah merupakan hal yang baru. Namun, kebanyakan penelitian berfokus pada berbagai inovasi pemanfaatan, biaya rendah dan penghematan daya. Penelitian-penelitian tersebut belum menyentuh pada aspek kemudahan pengembangan sistem, khususnya dalam konsep penambahan node. Indonesia, sebagai negara yang memiliki topografi wilayah yang bermacam-macam, membutuhkan sistem pemantauan cuaca terintegrasi dengan konsep pengumpulan data secara terpusat untuk mendapatkan gambaran secara lengkap.

Dalam penelitian ini dibangun sebuah sistem mini weather station portable yang diberi nama Amicagama (Alat Monitoring Cuaca Gadjah Mada). Sistem ini dibangun dengan konsep skalabilitas tinggi yang artinya sistem ini dirancang untuk dipakai secara publik, dengan setiap pengguna mampu mengelola node yang merupakan stasiun cuaca masing-masing. Pengelolaan oleh setiap pengguna disini memiliki arti bahwa setiap pengguna dapat mengatur data cuaca yang akan disampaikan, menambahkan node pada lokasi yang baru, serta dapat menghapus node pada suatu lokasi tertentu jika terjadi sesuatu yang tidak diinginkan.
\end{abstract}

Kata kunci-pemantauan cuaca, sistem peringatan dini, mikrokontroller, antarmuka pengguna

\begin{abstract}
Indonesia is a country that has unique weather that provides not only abundant natural resources but also can causes disasters at any time. To reduce the threat of losses, observing weather elements using a weather station is a solution that can be used. The development of systems related to environmental monitoring and weather stations is not new. However, most research focuses on various innovations in utilization, low cost and power savings. These studies have not touched on the aspect of ease of system development, especially in the concept of adding nodes. Indonesia, as a country with diverse regional topography, needs an integrated weather monitoring system with the concept of centralized data collection to get a complete picture.

In this study, a portable mini weather station system was built named Amicagama. This system is built with the concept of high scalability which means the system is designed to be used publicly, with each user able to manage the nodes which are their respective weather stations. Management by each user here means that each user can manage weather data to be submitted, add nodes at a new location, and can delete nodes at a certain location if something unexpected happens.
\end{abstract}

Keywords-weather monitoring, early warning system, microcontroller, user interface

Received October $4^{\text {th }}, 2019 ;$ Revised October $14^{\text {th }}, 2019 ;$ Accepted October $17^{\text {th }}, 2019$ 


\section{PENDAHULUAN}

Indonesia merupakan negara yang memiliki cuaca dan iklim yang khusus dan rumit. Hal ini disebabkan antara lain karena lokasi Indonesia yang berada pada daerah garis khatulistiwa, berbatasan dengan dua samudera yaitu Samudera Hindia dan Samudera Pasifik serta memiliki bentuk topografi orientasi dan struktur kepulauan [1]. Selain memberikan potensi kekayaan alam yang berlimpah, keunikan cuaca dan iklim yang dimiliki ini juga menyebabkan Indonesia diintai oleh bencana yang dapat sewaktu-waktu terjadi [2]. Selain itu, kondisi cuaca pada suatu daerah juga akan sangat berpengaruh terhadap kondisi masyarakatnya, mulai dari kegiatan sehari-hari hingga ke kegiatan industri[3]. Untuk mengatasi hal tersebut, pengamatan unsur cuaca menggunakan alat weather station biasanya menjadi salah satu solusi yang dapat digunakan untuk mengurangi ancaman kerugian yang mungkin terjadi [4][5]. Namun demikian, peralatan yang ada saat ini masih belum mencukupi, baik dalam kuantitas maupun dalam kualitas, agar dapat diimplementasikan pada berbagai kondisi alam maupun tatanan masyarakat Indonesia.

Pengembangan sistem terkait dengan pemantauan lingkungan pada umumnya, dan stasiun cuaca yang memiliki ukuran kecil (mini weather station) pada khususnya, bukan merupakan hal yang baru. Secara umum, keilmuan tentang pengembangan sistem pemantauan lingkungan lebih berfokus pada berbagai inovasi terkait dengan pemanfaatannya. Beberapa pemanfaatannya, selain untuk mengamati cuaca, sistem pemantauan lingkungan juga digunakan antara lain untuk sistem peringatan dini, seperti peringatan dini pada kebakaran [6], banjir [7][8], gempa bumi [9][10][11] ataupun tanah longsor [12]. Selain itu pemanfaatan sistem pemantauan lingkungan juga dapat digunakan sebagai kelengkapan pada gedung ramah energi [13].

Selain ditinjau dari pemanfaatannya, beberapa penelitian juga sudah membahas mengenai pengembangan sistem pemantauan lingkungan dengan biaya yang rendah [10][14][15][16]. Dari berbagai pengembangan sistem pemantauan cuaca maupun deteksi dini dan peringatan dini bencana, terdapat satu hal yang penting terutama bagi pengguna yaitu penyampaian informasi yang diperoleh dari sistem kepada penggunanya. Proses penyampaian informasi atau pengiriman data pada sistem pemantauan cuaca tersebut memanfaatkan konsep Internet of Thing (IoT) [15][17][18][19][20].

Dalam kaitannya dengan konsep pengiriman data tersebut, beberapa peneliti juga telah mengembangkan konsep mini weather station menjadi suatu sistem untuk mengoleksi data secara terpusat dengan berbagai stasiun yang ditempatkan di titik-titik yang tersebar [21][22]. Pada dasarnya sistem-sistem yang dikembangkan tersebut menggunakan konsep pengumpulan data terpusat dari titik-titik yang tersebar dengan data sensor tertentu yang ingin diamati. Rancangan tersebut menguntungkan dalam hal spasio-temporal, dimana data akan memiliki resolusi ruang dan waktu yang bagus untuk menggambarkan aktivitas dari besaran yang diamati secara lebih lengkap[23].

Dari berbagai pustaka yang telah ditinjau, sistem-sistem yang dikembangkan lebih berfokus pada tiga bahasan, yaitu rendahnya biaya, pengembangan sensor untuk deteksi bencana tertentu, maupun mekanisme untuk penyampaian informasi yang sangat tergantung pada jenis informasinya. Sistem-sistem tersebut belum menyentuh pada aspek kemudahan pengembangan sistem, khususnya dalam konsep penambahan node. Terlebih lagi, di Indonesia sendiri, meskipun telah marak dikembangkan stasiun mini oleh masing-masing peneliti atau pengembang, belum ada konsep pengumpulan data secara terpusat untuk mendapatkan gambaran secara lengkap.

Indonesia, sebagai negara yang memiliki topografi wilayah yang bermacam-macam, membutuhkan suatu sistem pemantauan cuaca terintegrasi dengan kekhasannya sendiri. Salah satu fitur yang diperlukan dalam sistem pemantauan cuaca tersebut adalah mudahnya dilakukan penambahan stasiun cuaca yang baru yang juga dapat langsung terhubung ke sistem utama. Oleh karena itu, dalam penelitian ini dibangun suatu sistem terintegrasi yang secara piranti keras maupun piranti lunak mudah untuk dikembangkan, serta mudah untuk digabungkan ke sistem

IJEIS Vol. 9, No. 2, October 2019: 203 - 214 
yang telah ada. Dengan fitur tersebut, maka piranti baru yang terpasang akan menjadi bagian dari sistem yang telah ada. Dengan demikian semua data yang dihasilkan oleh semua piranti dapat diakses bersama-sama dengan data-data dari piranti lain yang telah terpasang sebelumnya.

\section{METODE PENELITIAN}

\subsection{Konsep Sistem}

Internet of Things adalah sebuah paradigma yang memandang pergeseran teknologi internet dari internet tradisional ke skenario pemanfaatan internet untuk menghubungkan berbagai objek [24], yang kemudian paradigma tersebut menjadi bagian penting dari perkembangan teknologi dalam kehidupan manusia [25]. Salah satu hal yang dapat kita lihat dari efek paradigma tersebut adalah teknologi baru yang terus muncul dan semakin banyak pula objek yang dapat terhubung ke internet setiap harinya [26][27]. Salah satu pemanfaatan dari teknologi Internet of Things adalah munculnya teknologi weather station [15][17][18][19][20].

Amicagama (Alat Monitoring Cuaca Gadjah Mada) merupakan sebuah sistem yang dibangun dengan memanfaatkan teknologi Internet of Things untuk dapat menghimpun data cuaca dari berbagai wilayah di Indonesia secara khusus, meskipun secara teori dapat digunakan untuk lokasi dimana saja. Sistem ini dikembangkan dengan semangat keterbukaan data, artinya siapapun diharapkan mampu berkontribusi dalam memberikan data dan juga memanfaatkan data tersebut. Amicagama dikembangkan dengan konsep skalabilitas tinggi yang artinya sistem ini dirancang untuk dipakai secara publik, dengan setiap pengguna mampu mengelola node yang merupakan stasiun cuaca masing-masing. Pengelolaan oleh setiap pengguna disini memiliki arti bahwa setiap pengguna dapat mengatur data cuaca yang akan disampaikan, menambahkan node pada lokasi yang baru, serta dapat menghapus node pada suatu lokasi tertentu jika terjadi sesuatu yang tidak diinginkan. Oleh karena itu, sistem Amicagama dibuat dengan konsep yang mudah digunakan dan dioperasikan oleh berbagai kalangan masyarakat.

Sistem Amicagama terdiri dari perangkat keras sensor node dan perangkat lunak dashboard pengguna. Perangkat keras sensor node digunakan untuk mendeteksi keadaan cuaca suatu lokasi yang kemudian akan dikirimkan ke basis data sistem. Data yang ada dalam basis data sistem dapat diamati oleh pengguna melalui dashboard sistem. Selain untuk menampilkan data sensor, dashboard sistem juga digunakan untuk melakukan pendaftaran pengguna. Pengguna yang telah mendaftar akan mendapatkan hak untuk dapat menambahkan sensor node agar data node tersebut dapat ditampilkan dalam dashboard. Sementara itu, bagi para pengguna yang belum mendaftarkan diri akan tetap dapat mengakses dashboard sistem namun hanya dapat melihat data sensor node yang ada saja.

\subsection{Perancangan Sensor node}

Proses perancangan sensor node dibagi kedalam dua bagian, yaitu perancangan perangkat keras sensor node dan perancangan perangkat lunak sensor node. Perangkat keras sensor node terdiri dari mikrokontroller sebagai otak sensor node, sensor-sensor untuk mendeteksi cuaca, keypad sebagai piranti masukan pengguna, LCD untuk menampilkan pesan ke pengguna, dan regulator daya. Diagram blok perangkat keras sistem sensor node disajikan pada Gambar 1.

Mikokontroller sebagai otak sensor node berfungsi untuk membaca data-data dari sensor cuaca untuk kemudian dikirimkan ke server. Pembacaan data sensor oleh mikrokontroler dilakukan dengan protokol serial dan $\mathrm{I}^{2} \mathrm{C}$ sesuai dengan jenis sensor. Protokol komunikasi antara mikrokontroller dengan komponen lainnya dapat dilihat dalam Gambar 1.

Setelah semua data sensor didapatkan, selanjutnya mikrokontroler akan mengirimkan data-data tersebut ke server. Data-data yang telah terkumpul di dalam server selanjutnya akan ditampilkan ke dashboard sistem agar mudah diamati oleh pengguna. Pengiriman data ke server dilakukan dengan cara menyusun data-data sensor kedalam format JSON untuk kemudian 
dikirimkan melalui komunikasi HTTP POST. Format urutan pengiriman data sensor adalah ID; T; H; Lx; P; Lo; Lat, dengan masing-masing variabel adalah:
ID $\quad$ : ID node
$\mathrm{T} \quad$ : data suhu dalam derajat celcius
$\mathrm{H} \quad$ : data kelembaban udara
Lx : data intensitas cahaya
$\mathrm{P} \quad$ : data tekanan udara
Lo : koordinat Longitude dari node
Lat : koordinat Lattitude dari node.

Secara keseluruhan, program sensor node yang ditanamkan dalam mikrokontroller dapat digambarkan dalam diagram alir pada Gambar 2.

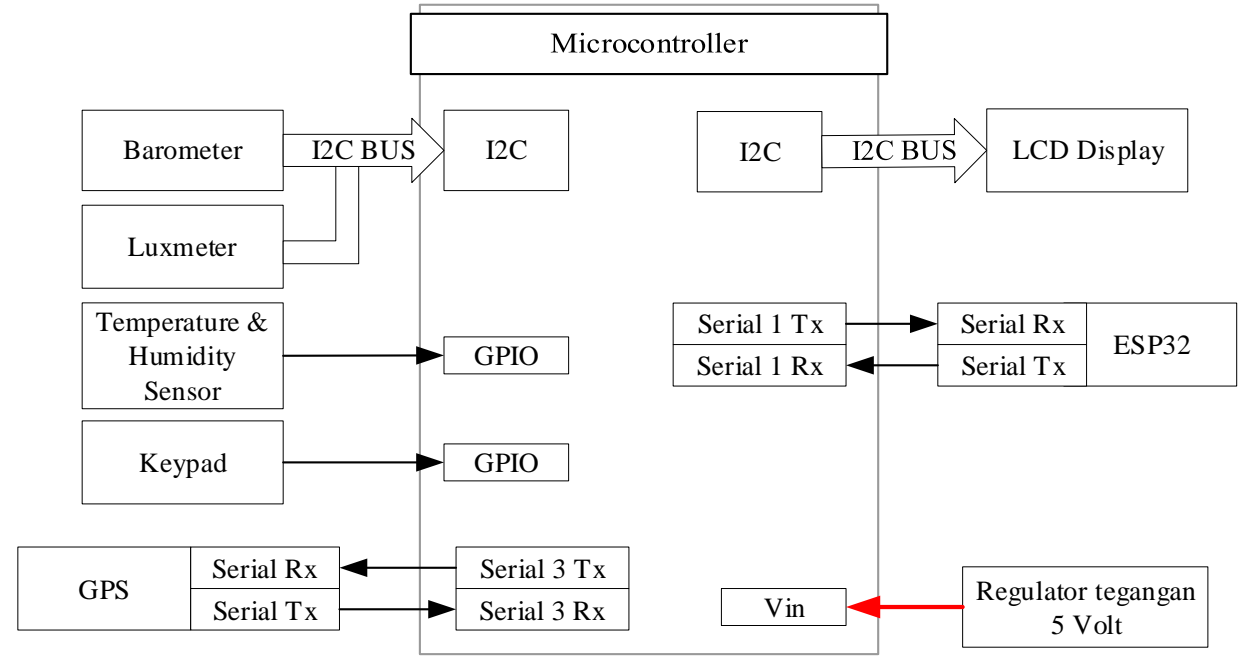

Gambar 1 Diagram blok perangkat keras sensor node

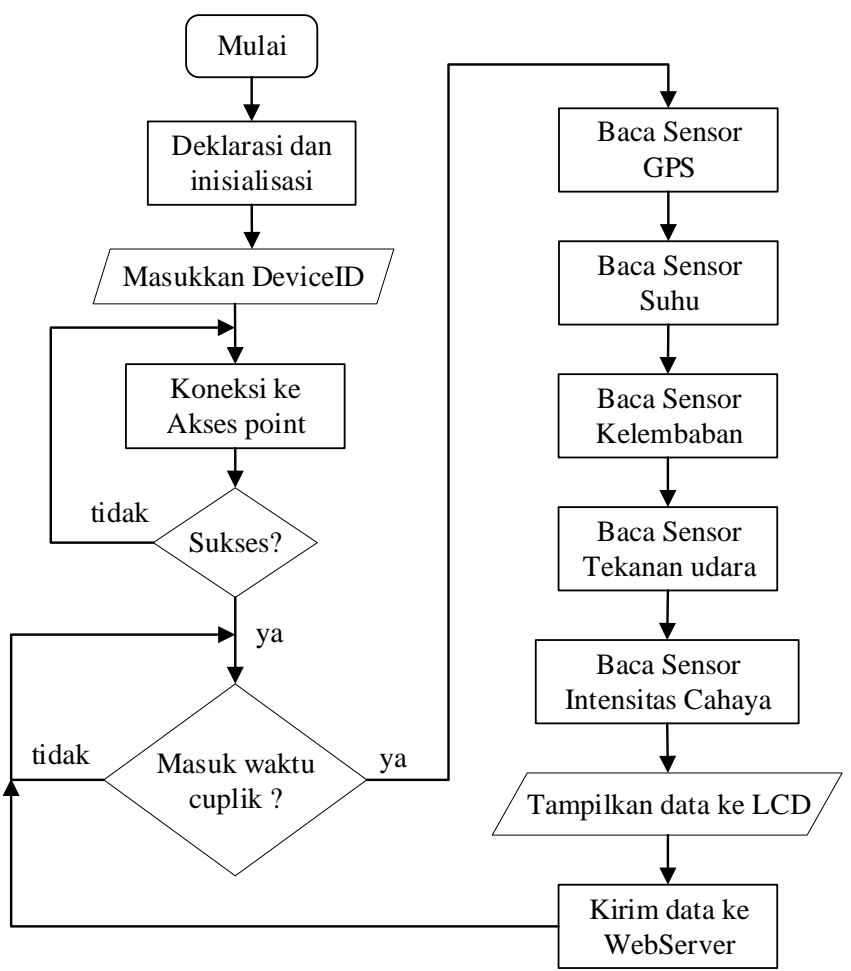

Gambar 2 Diagram alir program sensor node 


\subsection{Perancangan Dashboard Sistem}

Sensor node yang dikembangkan berfungsi untuk mengumpulkan data cuaca terkait dimana data-data tersebut perlu didiseminasikan ke masyarakat umum. Diseminasi data-data tersebut dilakukan melalui website yang dikembangkan pada laman http://amicagama.id. Secara keseluruhan, sistem yang dikembangkan selain mengumpulkan dan menyampaikan data terkait juga memiliki keunggulan dalam hal penambahan node melalui web tersebut. Penambahan node secara mudah dan dapat dilakukan oleh siapa saja dengan maksud bahwa sistem ini secara keseluruhan merupakan sistem inklusif dimana siapa saja dapat menyampaikan data di lokasinya dan siapa saja dapat melihat informasi di lokasi manapun yang telah terdaftar. Untuk itu, dikembangkan dashboard yang memfasilitasi semua hal tersebut. Konsep rancangan dashboard ditunjukkan pada Gambar 3.

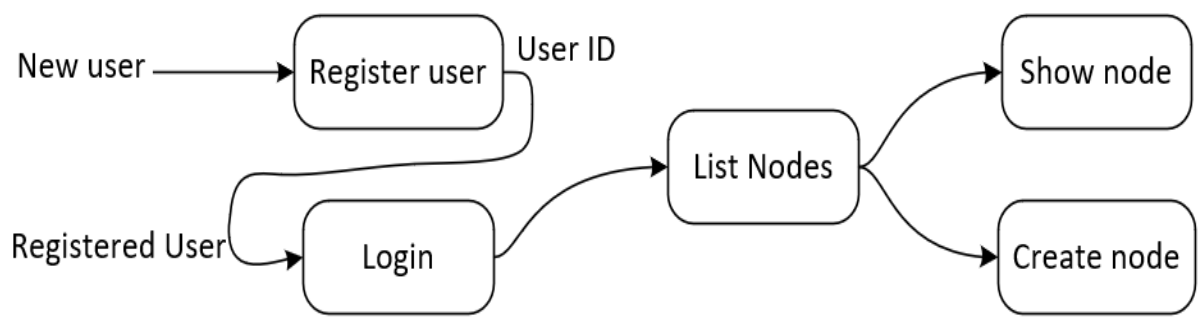

Gambar 3 Diagram blok rancangan dashboard sistem

\subsubsection{Rancangan menu dashboard}

Dashboard yang dikembangkan secara umum memiliki beberapa bagian utama, antara lain adalah sebagai berikut:

1. Laman pendaftaran pengguna

2. Laman login

3. Laman manajemen node

Laman pendaftaran dan login user digunakan oleh user untuk masuk ke dalam dashboard amicagama untuk mengelola node melalui laman manajemen node. Secara umum terdapat tiga menu utama di dalam dashboard pengguna, yaitu home, devices, dan maps. Menu home digunakan untuk melihat data dari seluruh node terkait. Menu devices digunakan untuk melihat seluruh daftar node yang telah didaftarkan oleh user tersebut. Pengguna juga dapat melihat (show), mengedit (edit), dan menghapus (delete) node tertentu. Selain itu, user juga dapat mendaftarkan node baru melalui menu Create node. Menu maps digunakan untuk mendaftarkan lokasi dari node jika node terkait tidak memiliki atau tidak mengaktifkan sensor GPS-nya.

\subsubsection{Rancangan visualisasi dashboard}

Dashboard yang dirancang menyajikan tampilan dashboard secara umum. Fungsi utama dari dashboard yang dikembangkan adalah untuk diseminasi data. Versi awal dari amicagama menyediakan nilai-nilai suhu (temperature), kelembaban udara (humidity), serta tekanan udara (barometer) dalam nilai sesaat maupun dalam grafik riwayat selama satu hari terakhir.

\subsubsection{Rancangan basis data sistem}

Empat tabel utama yang diperlukan dalam basis data untuk amicagama terdiri dari user, nodes, measurements, dan one_signals, seperti ditunjukkan pada gambar 4. Masing-masing dari tabel tersebut menyimpan informasi pengguna, node-node yang dimiliki oleh pengguna, variabel ukur yang terdapat pada masing-masing node, serta tabel untuk pendataan registrasi pengguna. 


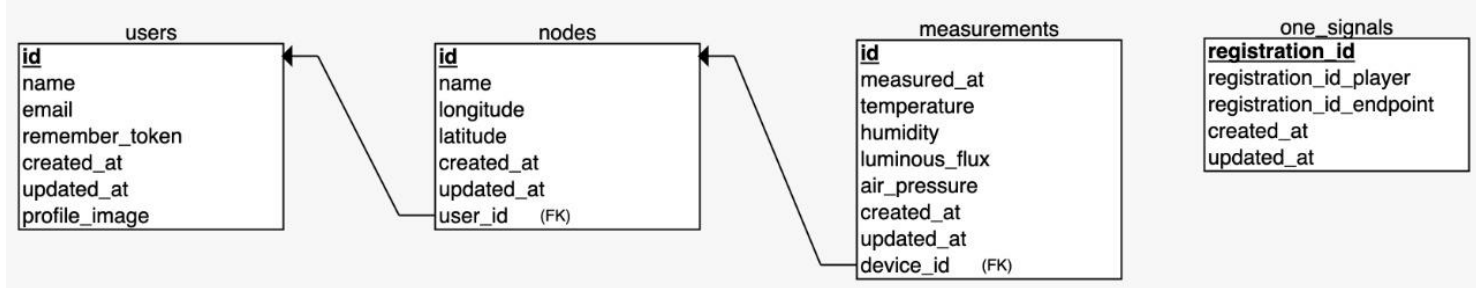

Gambar 4 Basis data sistem

\section{HASIL DAN PEMBAHASAN}

\subsection{Implementasi Perangkat Keras Sensor Node}

Implementasi perangkat keras sensor node terdiri bagian elektronis dan bagian kotak sensor node. Bagian elektronis digunakan untuk menghubungkan seluruh komponen sensor node, sedangkan bagian kotak sensor node digunakan untuk melindungi elektronis dan mempermudah penggunaan sensor node. Bagian kotak sensor node terbuat dari plastic PLA dengan ukuran panjang $12,5 \mathrm{~cm}$, lebar $8,3 \mathrm{~cm}$ dan tinggi $4 \mathrm{~cm}$. Tampilan komponen-komponen penyusun sensor node beserta implementasinya disajikan pada Gambar 5.

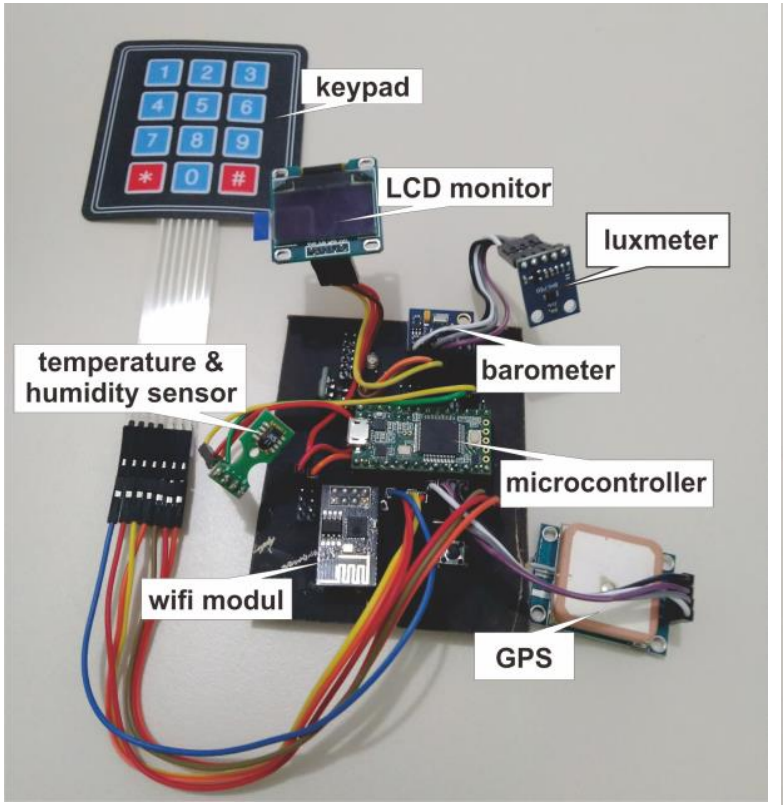

(a)

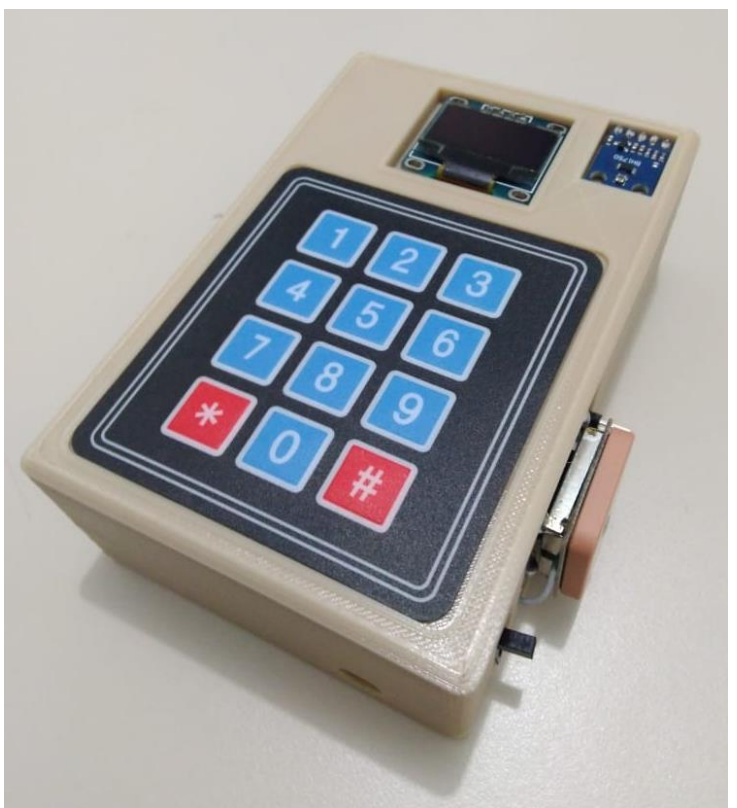

(b)

Gambar 5 Implementasi perangkat keras sensor node: (a) elektronis sensor node, (b) sensor node setelah diberi pelindung kotak.

Tabel 1 menampilkan daftar komponen penyusun perangkat keras sensor node beserta fungsinya. Sebagaimana yang telah disajikan pada Tabel 1, sebuah sensor node memiliki empat buah sensor untuk mendeteksi keadaan cuaca lingkungan, yaitu sensor intensitas cahaya GY302, barometer MS5611, SHT11 dan GPS Neo M8N. Dengan empat buah sensor tersebut kemudian didapatkan data-data lingkungan berupa intensitas cahaya, tekanan udara, suhu udara dan kelembaban udara serta koordinat lokasi sensor node dalam bentuk longitude dan latitude. Setelah semua data sensor dapat dibaca oleh mikrokontroller, selanjutnya data tersebut akan dikirimkan oleh mikrokontroller ke server untuk kemudian ditampilkan pada dashboard sistem. 
Tabel 1 Komponen penyusun perangkat keras sensor node

\begin{tabular}{|c|l|l|}
\hline No & \multicolumn{1}{|c|}{ Nama Komponen } & \multicolumn{1}{|c|}{ Fungsi } \\
\hline 1 & Teensy 3.2 & $\begin{array}{l}\text { Sebagai perangkat pemrosesan data, mulai dari } \\
\text { membaca data dari sensor hingga mengirimkan ke } \\
\text { server (nikrokontroller). }\end{array}$ \\
\hline 2 & Sensor GY302 & $\begin{array}{l}\text { Sebagai komponen yang digunakan untuk } \\
\text { mendeteksi intensitas cahaya (luxmeter). }\end{array}$ \\
\hline 3 & Sensor MS5611 & $\begin{array}{l}\text { Sebagai komponen yang digunakan untuk } \\
\text { mendeteksi tekanan udara (barometer). }\end{array}$ \\
\hline 4 & Sensor SHT11 & $\begin{array}{l}\text { Sebagai komponen yang diguakan untuk membaca } \\
\text { suhu udara dan kelembaban udara (sensor suhu dan } \\
\text { kelemaban). }\end{array}$ \\
\hline 5 & Sensor GPS Neo M8N & $\begin{array}{l}\text { Sebagai komponen yang digunakan untuk } \\
\text { mendeteksi lokasi sensor node dalam bentuk } \\
\text { longitude dan latitude. }\end{array}$ \\
\hline 6 & LCD Oled 0,96" inch & $\begin{array}{l}\text { Sebagai komponen yang digunakan untuk } \\
\text { menampilkan pesan kepada pengguna. }\end{array}$ \\
\hline 7 & Keypad 3x4 & $\begin{array}{l}\text { Sebagai komponen yang digunakan untuk } \\
\text { mendapatkan masukan dari pengguna. }\end{array}$ \\
\hline 8 & ESP8266 & $\begin{array}{l}\text { Sebagai komponen modul wifi yang digunakan untuk } \\
\text { mengirimkan data ke server. }\end{array}$ \\
\hline 9 & UBEC 5 Volt 3Ampere & Sebagai regulator daya. \\
\hline
\end{tabular}

Gambar 6 menunjukkan cara pengiriman data dari sensor node ke server. Pengiriman dilakukan dengan menggunakan metode POST ke alamat dengan host amicagama.id. Format pengiriman diawali dengan mengirimkan header POST yang berisikan jenis konten pengiriman, alamat host, jenis koneksi dengan host, dan jumlah karakter data yang akan dikirim. Setelah header didefinisikan selanjutnya akan dikirim isi konten atau body paket berupa data dari sensor node. Data yang dikirim adalah device_id node, suhu, kelembaban, intensitas cahaya, tekanan udara, longitude, dan latitude. Data tersebut dimasukkan sesuai dengan key yang telah ditentukan oleh server. Pengiriman data menggunakan ESP8266 diawali dengan perintah AT+CIPSTART untuk menghubungkan node dengan server. Dalam penelitian ini koneksi yang digunakan adalah koneksi TCP dengan port 80. Header dan body paket yang telah dibuat akan dikirimkan dengan menggunakan perintah AT+CIPSEND yang diikuti jumlah karakter keseluruhan.

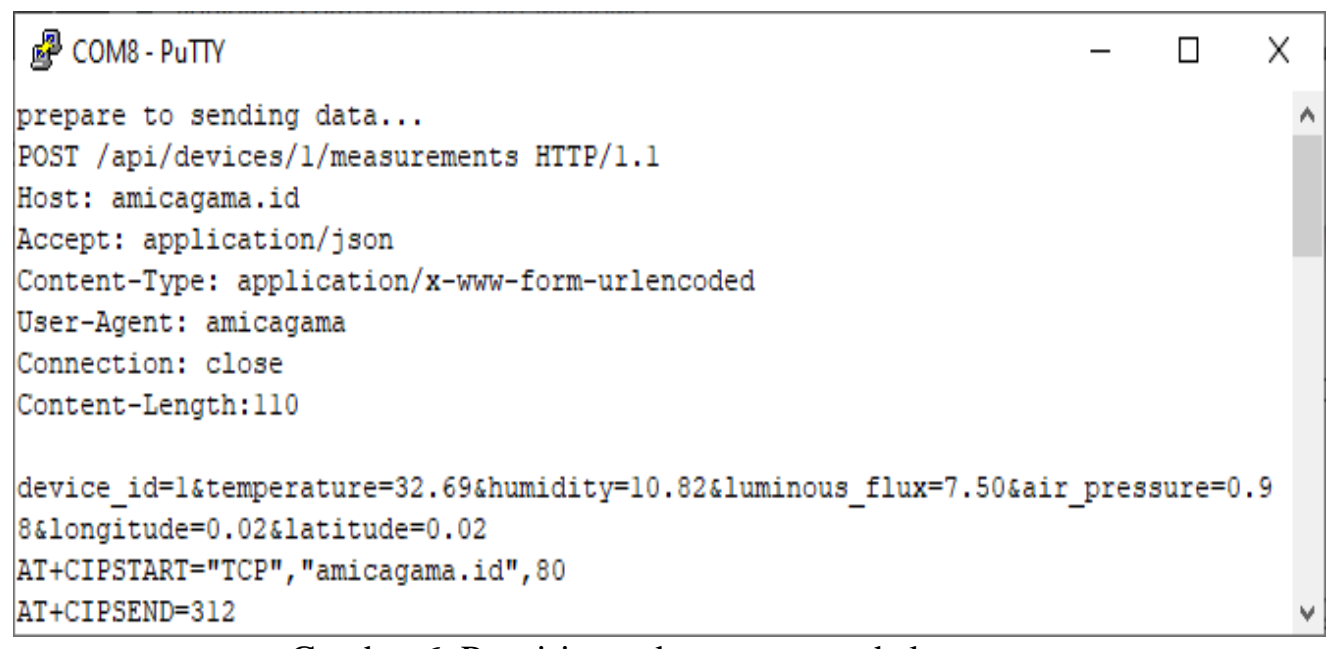

Gambar 6 Pengiriman data sensor node ke server 


\subsection{Implementasi Dashboard Sistem}

Dashboard yang dikembangkan pada sistem amicagama memiliki fungsi utama untuk diseminasi hasil pengukuran data cuaca dari sensor-sensor yang terdapat dalam suatu node. Satu user dapat mendaftarkan banyak node sekaligus sebagai pengelola dari node-node tersebut. Data utama ketika user mendaftarkan node baru adalah lokasi dari node tersebut. Gambar 7 menunjukkan beberapa node yang dikelola oleh seorang user, sedangkan pada Gambar 8 ditunjukkan peta dimana lokasi masing-masing node terlihat. Lokasi node tersebut dapat dimasukkan secara manual oleh user namun juga dapat diupdate secara otomatis jika node tersebut memiliki sensor GPS yang terpasang.

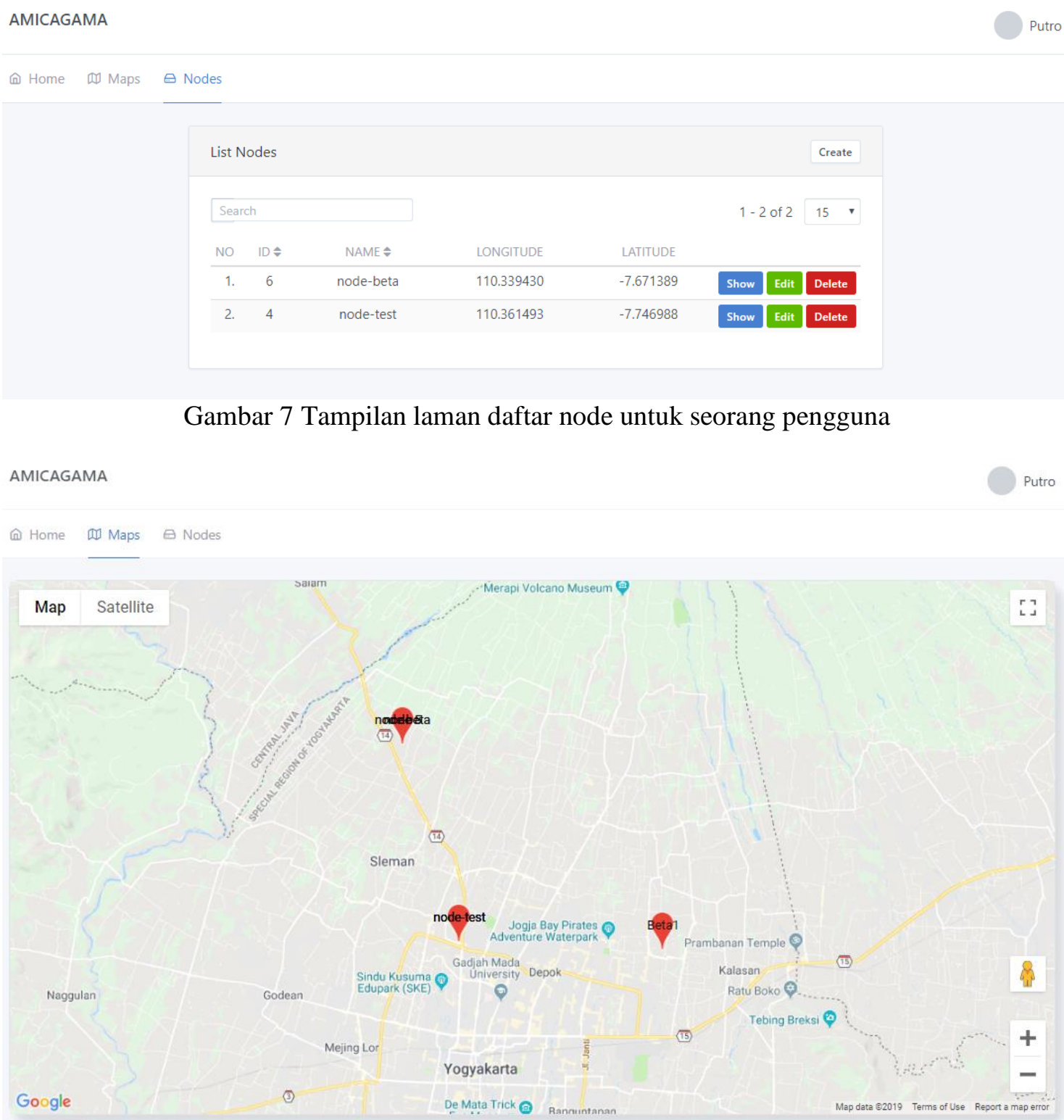

Gambar 8 Tampilan lokasi node-node yang telah terdaftar

Peta dan pengelolaan node tersebut menunjukkan kemudahan proses diseminasi informasi cuaca yang disampaikan kepada masyarakan umum dengan mudah. Penambahan lokasi node yang mudah sesuai dengan tujuan amicagama, yaitu stasiun cuaca mini yang ramah pengguna. Ketika sistem ini dipakai secara luas, maka diseminasi informasi akan lebih menjangkau daerah-daerah terjauh, terluar, terdepan dengan mudah dan akses yang terpusat. 
Selain penambahan node, diseminasi informasi dalam amicagama juga didukung oleh adanya fitur penampilan data ukur cuaca dalam bentuk grafis. Visualisasi dalam bentuk grafis menunjukkan nilai ukur tunggal maupun riwayat selama beberapa hari dalam bentuk grafik. Untuk versi amicagama saat ini, data ukur cuaca yang ditampilkan adalah berupa suhu, kelembaban, intensitas cahaya, dan tekanan udara seperti ditunjukkan pada Gambar 9. Kemudahan yang ditawarkan dalam akses data ini juga dalam bentuk kompatibilitas multiplatform, dimana data yang ditampilkan juga akan menyesuaikan perangkat seperti telepon genggam sehingga lebih ramah pengguna. Akses melalui telepon genggam sangat penting mengingat saat ini internet dalam telepon genggam merupakan satu hal yang tidak terpisahkan dari kehidupan sehari-hari.

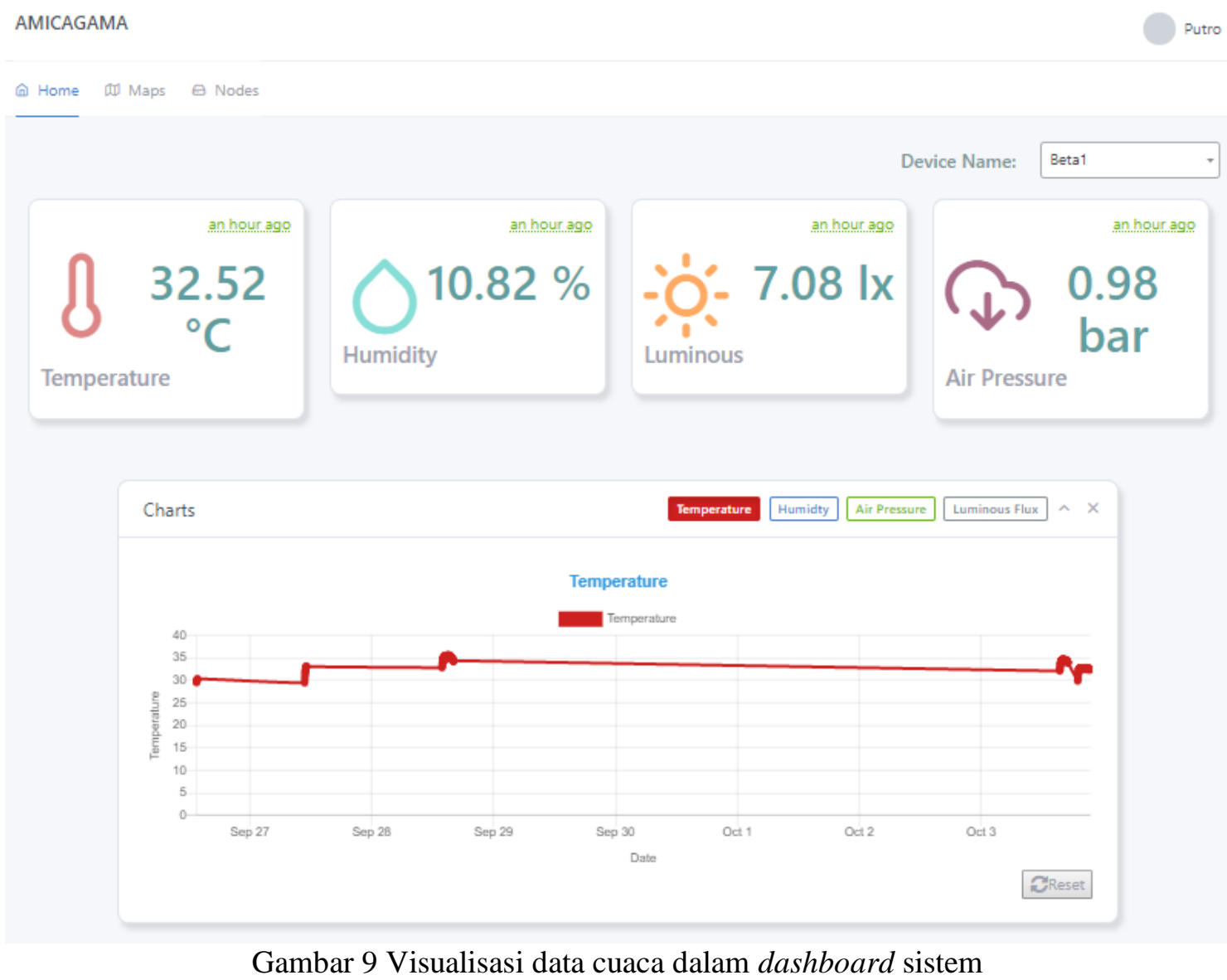

\subsection{Diskusi}

Sistem Amicagama dikembangkan berdasar konsep pengumpulan informasi dengan tingkat skalabilitas yang tinggi. Skalabilitas dalam hal ini berarti bahwa sistem ini dapat melakukan penambahan maupun pengurangan node dengan mudah. Hal ini telah ditunjukkan dengan adanya beberapa node yang dapat dikelola oleh seorang pengguna dengan tampilan dari peta dalam dashboard menunjukkan lokasi dari masing-masing dashboard. Selain itu, untuk mendukung skalabilitas dan diseminasi informasi bagi pengguna maupun umum, amicagama dilengkapi dengan tampilan berbasis web maupun tampilan berbasis telepon genggam. Hal ini mendukung kemudahan akses dan pengelolaan pagi pengguna dan masyarakat umum.

Untuk mendukung pengumpulan informasi, amicagama menawarkan node berupa perangkat keras dengan wujud kotak yang terdiri dari mikrokontroler dan sensor terkait. Masing-masing sensor berfungsi untuk mengambil data cuaca yang dibutuhkan, sesuai dengan yang didaftarkan oleh pengguna sebagai pemilik node ke server amicagama. Kotak node memiliki tampilan luar berupa LCD 0,96" dengan keypad numerik yang berfungsi untuk melihat 
data sensor. Sensor node juga dikembangkan menggunakan komponen-komponen dengan harga terjangkau, namun tetap memiliki kemampuan deteksi lingkunangan dan ketahanan yang baik. Dengan demikian, sensor diharapkan mampu membaca keadaan lingkungan dengan akurasi yang baik dan juga mampu bertahan lama selama digunakan namun tetap dapat dibangun dan dioperasionalkan oleh berbagai kalangan masyarakat.

Tabel 2 Contoh hasil pengukuran

\begin{tabular}{|c|c|c|c|c|c|c|c|}
\hline device_id & measured_at & temp & hum & flux & air_press & long & lat \\
\hline 1 & $3 / 10 / 1916: 44$ & 34.43 & 26.07 & 1.67 & 0.98 & 110.44 & -7.75 \\
\hline 1 & $3 / 10 / 1916: 45$ & 34.35 & 26.07 & 0.83 & 0.98 & 110.44 & -7.75 \\
\hline 1 & $3 / 10 / 1916: 46$ & 34.34 & 26.07 & 0.42 & 0.98 & 110.44 & -7.75 \\
\hline 1 & $3 / 10 / 1916: 47$ & 34.34 & 26.07 & 0.42 & 0.98 & 110.44 & -7.75 \\
\hline 1 & $3 / 10 / 1916: 48$ & 34.41 & 26.07 & 2.92 & 0.98 & 110.44 & -7.75 \\
\hline 1 & $3 / 10 / 1916: 49$ & 34.35 & 26.07 & 2.92 & 0.98 & 110.44 & -7.75 \\
\hline 1 & $3 / 10 / 1916: 50$ & 34.28 & 26.07 & 3.33 & 0.98 & 110.44 & -7.75 \\
\hline
\end{tabular}

Tabel 2 menampilkan contoh data hasil pengukuran salah satu node dengan device id yaitu 1. Pengukuran tersebut dilakukan pada tanggal 3-10-2019 dengan hasilnya rata-rata suhu $34,43^{\circ} \mathrm{C}$, kelembaban $26,07 \%$, kecerahan $1,25 \mathrm{~lx}, 0.98$ bar. Lokasi perangkat juga terdapat dalam tabel pengukuran dengan data longitude dan latitude yaitu 110,4 dan -7,75. Data tersebut menunjukkan bahwa pengukuran dilakukan setiap 1 menit sekali dengan data yang relatif sama untuk tiap pengukurannya di rentang waktu tersebut. Seperti yang telah disampaikan sebelumnya, nilai device id akan bernilai sama untuk sebuah device yang sama. Apabila ada device baru yang ditambahkan maka nilai device id akan dibuat ulang oleh sistem dengan sifat yang unik, tidak dapat berulang, dan menjadi id dari node baru yang didaftarkan tersebut.

Pengukuran suhu dapat dipengaruhi oleh sinar matahari. Jika pada siang hari maka suhu akan cenderung tinggi dibanding dengan suhu pada malam hari atau jika terjadi hujan. Pengukuran suhu tersebut dapat mengindikasikan tekanan udara di sekitar. Semakin tinggi suhu udara maka semakin kecil tekanan udaranya. Kelembapan akan mengalami peningkatan ketika akan terjadi hujan sebagai akibat peningkatan konsentrasi uap air di udara. Sementara pengukuran tekanan udara pada sensor tersebut merupakan tekanan udara relatif yang menunjukkan ketiggian terhadap permuakaan laut. Sensor cahaya sebagai data untuk menggambarkan kondisi malam, siang, dan ketika terjadi mendung.

\section{KESIMPULAN}

Sistem Amicagama adalah sistem pemantauan cuaca berukuran kecil yang memanfaatkan konsep internet of things untuk mendukung pengumpulan informasi cuaca di Indonesia. Sensor node yang dibangun memiliki kemampuan untuk mendeteksi kondisi lingkungan yaitu berupa suhu udara, kelembaban udara, tekanan udara, intensitas cahaya dan lokasi dipasangnya sensor node tersebut. Selain itu, sensor node juga dilengkapi dengan perangkat masukan maupun keluaran berupa LCD dan keypad untuk mempermudah pengguna dalam mengoperasikannya. Sebagai penampil data, dashboard sistem Amicagama dibangun. Dashboard sistem Amicagama dirancang sederhana namun tetap mudah digunakan oleh pengguna, baik untuk mengamati lingkungan berdasarkan data yang ada, maupun untuk melakukan pemeliharaan node berupa penambahan maupun pengurangan node. Hal tersebut dikarenakan sistem Amicagama dibangun dengan menerapkan konsep skalabilitas tinggi, yaitu sistem dibangun dan dirancang agar mudah dikelola, khususnya terkait penambahan dan pengurangan sensor node.

IJEIS Vol. 9, No. 2, October 2019 : 203 - 214 


\section{UCAPAN TERIMA KASIH}

Penulis ingin mengucapkan terima kasih kepada Universitas Gadjah Mada atas dukungan finansial yang telah diberikan melalui Kegiatan Peningkatan Kapasistas Peneliti Dosen Muda Tahun 2019 dengan Nomor : 3995/UN1/DITLIT/DIT-LIT/LT/2019.

\section{DAFTAR PUSTAKA}

[1] S. Wirjohamidjojo and Y. Swarinoto, Iklim Kawasan Indonesia (Dari Aspek Dinamik Sinoptik). Jakarta, Indonesia: Badan Meteorologi Klimatologi dan Geofisika, 2010.

[2] A. M. Hadi, B. D. Meidityawati, L. Møller, and U. D. Lasmana, Kesiapsiagaan Bencana Berbasis Masyarakat Strategi dan Pendekatan, I. Jakarta, Indonesia: Palang Merah Indonesia Pusat, 2007.

[3] C. Lu, D. Lin, J. Jia, and C. K. Tang, "Two-Class Weather Classification," IEEE Trans. Pattern Anal. Mach. Intell., vol. 39, no. 12, pp. 2510-2524, Dec. 2017.

[4] D. Jiang, Y. Tian, and L. Huang, "Design of shipboard complex weather warning system in the Yangtze River," in ICTIS 2015 - 3rd International Conference on Transportation Information and Safety, Proceedings, 2015, pp. 607-610.

[5] A. Serkov, S. Nikitin, V. Kravchenko, and V. Knyazev, "Thunderstorm hazards early warning system," in 2015 2nd International Scientific-Practical Conference Problems of Infocommunications Science and Technology, PIC S and T 2015 - Conference Proceedings, 2015, pp. 137-138.

[6] R. H. Eltom, E. A. Hamood, A. A. A. Mohammed, and A. A. Osman, "Early Warning Firefighting System Using Internet of Things," in 2018 International Conference on Computer, Control, Electrical, and Electronics Engineering, ICCCEEE 2018, 2018.

[7] A. Dersingh, "Design and development of a flood warning system via mobile and computer networks," in International Conference on Electronics, Information, and Communications, ICEIC 2016, 2016.

[8] S. Jayashree, S. Sarika, A. L. Solai, and S. Prathibha, "A novel approach for early flood warning using android and IoT," in Proceedings of the 2017 2nd International Conference on Computing and Communications Technologies, ICCCT 2017, 2017, pp. 339-343.

[9] A. Alphonsa and G. Ravi, "Earthquake early warning system by IOT using Wireless sensor networks," in Proceedings of the 2016 IEEE International Conference on Wireless Communications, Signal Processing and Networking, WiSPNET 2016, 2016, pp. 1201-1205.

[10] M. Klapez, C. A. Grazia, S. Zennaro, M. Cozzani, and M. Casoni, "First Experiences with Earthcloud, a Low-Cost, Cloud-Based IoT Seismic Alert System," in International Conference on Wireless and Mobile Computing, Networking and Communications, 2018, vol. 2018-October, pp. 262-269.

[11] H. Tariq, F. Touati, M. A. E. Al-Hitmi, D. Crescini, and A. Ben Manouer, "Design and Implementation of Programmable Multi-Parametric 4-Degrees of Freedom Seismic Waves Ground Motion Simulation IoT Platform,” 2019, pp. 1935-1939.

[12] L. Awaludin and O. A. Dhewa, "Low Cost Sensor Node Device for Monitoring Landslides," IJEIS (Indonesian J. Electron. Instrum. Syst., vol. 8, no. 2, p. 201, 2018.

[13] C. Morón, J. P. Diaz, D. Ferrández, and P. Saiz, "Design, development and implementation of a weather station prototype for renewable energy systems," Energies, vol. 11, no. 9, 2018.

[14] G. Piñeres-Espitia, A. Cama-Pinto, D. De La Rosa Morrón, F. Estevez, and D. CamaPinto, "Design of a low cost weather station for detecting environmental changes," Rev. Espac., vol. 38, no. 59, pp. 13-29, 2017.

[15] R. K. M. Math and N. V. Dharwadkar, "IoT Based low-cost weather station and 
monitoring system for precision agriculture in India," in Proceedings of the International Conference on I-SMAC (IoT in Social, Mobile, Analytics and Cloud), I-SMAC 2018, 2019, pp. 81-86.

[16] M. Nsabagwa, M. Byamukama, E. Kondela, and J. S. Otim, "Towards a robust and affordable Automatic Weather Station," Dev. Eng., vol. 4, p. 100040, Jan. 2019.

[17] M. Kusriyanto and A. A. Putra, "Weather Station Design Using IoT Platform Based On Arduino Mega," in ISESD 2018 - International Symposium on Electronics and Smart Devices: Smart Devices for Big Data Analytic and Machine Learning, 2019.

[18] R. K. Kodali and A. Sahu, "An IoT based weather information prototype using WeMos," in Proceedings of the 2016 2nd International Conference on Contemporary Computing and Informatics, IC3I 2016, 2016, pp. 612-616.

[19] L. Z. Turos, G. Csernath, and B. Csenteri, "Power Management in IoT Weather Station," in EPE 2018 - Proceedings of the 2018 10th International Conference and Expositions on Electrical And Power Engineering, 2018, pp. 133-138.

[20] E. R. Kaburuan, R. Jayadi, and Harisno, "A Design of IoT-based Monitoring System for Intelligence Indoor Micro-Climate Horticulture Farming in Indonesia," Procedia Comput. Sci., vol. 157, pp. 459-464, Jan. 2019.

[21] F. Meier, D. Fenner, T. Grassmann, M. Otto, and D. Scherer, "Crowdsourcing air temperature from citizen weather stations for urban climate research," Urban Clim., vol. 19, pp. 170-191, Jan. 2017.

[22] C. L. Muller et al., "Crowdsourcing for climate and atmospheric sciences: Current status and future potential," Int. J. Climatol., vol. 35, no. 11, pp. 3185-3203, 2015.

[23] L. Chapman, C. Bell, and S. Bell, "Can the crowdsourcing data paradigm take atmospheric science to a new level? A case study of the urban heat island of London quantified using Netatmo weather stations," Int. J. Climatol., vol. 37, pp. 3597-3605, 2016.

[24] A. Singh, A. Payal, and S. Bharti, "A walkthrough of the emerging IoT paradigm: Visualizing inside functionalities, key features, and open issues," Journal of Network and Computer Applications, vol. 143. Academic Press, pp. 111-151, 01-Oct-2019.

[25] M. Dachyar, T. Y. M. Zagloel, and L. R. Saragih, "Knowledge growth and development: internet of things (IoT) research, 2006-2018," Heliyon, vol. 5, no. 8, p. e02264, Aug. 2019.

[26] J. H. Nord, A. Koohang, and J. Paliszkiewicz, "The Internet of Things: Review and theoretical framework," Expert Systems with Applications, vol. 133. Pergamon, pp. 97108, 01-Nov-2019.

[27] F. Alkhabbas, R. Spalazzese, and P. Davidsson, "Characterizing Internet of Things Systems through Taxonomies: A Systematic Mapping Study," Internet of Things, vol. 7, p. 100084 , Sep. 2019. 